Editorial

\title{
Special Edition on Policing (at) the ESC Perspectives from the Lausanne School of Criminal Justice
}

\section{Combining Forensic Science and Criminology to Foster Innovation in Policing}

\author{
Céline Weyermann, Manon Jendly and Quentin Rossy
}

The School of Criminal Justice, known as the Ecole des sciences criminelles ${ }^{1}$ (ESC) in French, has a long history for an academic institution, dedicated to the study of crime in a broad sense. Affiliated to the University of Lausanne, Switzerland, it was founded by Archibald Rudolph Reiss in 1909 as the Institut de police scientifique ${ }^{2}$ and was affiliated since then, to the law faculty, renamed relatively recently as Faculté de droit, des sciences criminelles et d'administration publique. ${ }^{3}$ Reiss was a chemist passionate about photography, and more precisely judiciary photography. Very early, he understood that 'scientific police' was intrinsically linked to a legal framework and needed interdisciplinarity in order to address crime problems efficiently. In fact, Reiss already combined criminological and forensic science knowledge and was very close to police investigations, often joining policemen on the field.

This special issue of Policing relies on Reiss' heritage, as our mission was to propose an 'institutional edition' about the school. Thus, all contributions were written by scientists that have studied at some point in their career at the ESC. Some have followed the whole curriculum; others have carried out a master's degree after another academic programme (e.g. law, psychology, chemistry or biology). Some hold a $\mathrm{PhD}$ in forensic science or criminology and have embraced an academic career, while some others have become police inspectors or managers. All share a common affiliation. Hence, we immediately identified the risk of giving a self-centred vision of policing issues and we have tried to

School of Criminal Justice (ESC), Faculty of Law, Criminal Justice and Public Administration, University of Lausanne, Batochime, CH-1015 Lausanne, Switzerland. E-mail: celine.weyermann@unil.ch

${ }^{1}$ www.unil.ch/esc

${ }^{2}$ In English, The Institute of Scientific Police.

${ }^{3}$ In English, The Faculty of Law, Criminal Justice and Public Administration: http://www.unil.ch/fdca

Policing, pp. 1-4

doi:10.1093/police/pay002

(C) The Author(s) 2018. Published by Oxford University Press. All rights reserved.

For permissions please e-mail: journals.permissions@oup.com 
counterbalance this through a reflexive approach and provocative titles in the form of questions.

Indeed, the contributions share common points in their views of forensic science and criminology, the first focusing on physical and digital traces to reconstruct events; secondly, interested in behaviours, actors, and social reactions. Yet, this edition does not only depict one point of view, but many that are to some extent complementary, and sometimes also contradictory about the future of the institution, policing, criminology, and forensic science. Thus, this special issue shall be considered as a journey into a world under construction, paved with vivid confrontation. While readers shall discover very practical problems and leads presented by professionals close to the field, they might also come out of it with more questions than they imagined before starting reading.

As guest co-editors of this special issue, we represent this 'interdisciplinary movement' to study crime and translate research into the realm of practices. In many discussions we shared with colleagues in- and outside the school, we realized that beyond our differences, a problem-based approach appeared to be generally well accepted by all of us. This approach consists in (1) identifying and detecting the problem; (2) analysing its manifestations; (3) defining actions to solve it, and (4) evaluating their impacts. This structured approach may serve as a basis to apprehend the manifold bounds between forensic science, criminology, and policing. Most, if not all papers of this issue agreed that an approach centred on problem identification and resolution might be a better starting point to drive scientific research in both disciplines, rather than a focus on technological or analytical processes. If we use many techniques, metrics, and methods developed by other sciences (such as social, natural or information sciences), all of them are actually integrated with a global methodology focusing on problems and their resolutions. What are the relevant crime problems the world faces nowadays? What are the options to address them? And how can we develop critical thinking, adequate training, and practices in this field to address future problems and developments?

\section{Towards a collaborative problem- based approach}

As emphasized in Ribaux's opinion paper (2018, in this issue), crime dynamics are quickly evolving, becoming more global, adaptive, and complex. Ribaux first identified an increasingly digitalized world, with which academic and police institutions have difficulty to keep pace. Other contributions also discuss the need to improve empirical methods around both physical and massively generated digital traces. Case studies are used to illustrate how police investigation and management combine physical and digital traces to improve the prevention of crime phenomena and/or resolve cases (Casey and Jaquet-Chiffelle, 2018; Guéniat 2018, in this issue). The need for scientists and practitioners to develop structured tools for data collection and analysis from multiple sources is also stressed in order to improve the reliability of (cyber) crime detection and, consequently, the quality of the responses to crime (Caneppele and Aebi 2018; Grossrieder and Ribaux 2018, in this issue).

In this line of thought, several contributions suggested the monitoring of crime-related data such as waste (water), traces collected on burglaries, skimming or forgeries of identity documents, as well as information gathered on violent serial crimes. Such systematic approaches call for an information-led policing' through the gathering and exploitation of information for early detection, identification, and understanding of crime-related problems (Esseiva and Delémont, 2018; Grossrieder and Ribaux, 2018; Chopin et al., 2018, in this issue). These contributions suggest that recurrences and anomalies within the structure of an individual or collective behaviour involved in litigious activities will cause patterns that can be detected and interpreted. In this context, information is used in an intelligence-led 
policing framework to infer links and detect patterns that might then be used to define actions such as crime prevention.

Data and traces are not the sole core object of study that can bind forensic science and criminology. Identities and generalized human traceability also play a critical role to reconstruct criminal behaviours. In forensic science, identity-related information is used to link suspects and objects to criminal activities and guide the investigative and judiciary process to find and sentence authors. In criminology, criminal behaviours are also scrutinized to infer offender profiles, modus operandi and trajectories (e.g. 'criminal careers'). Casey and Jaquet-Chiffelle (2018, in this issue) propose a general 'identity-related model' to classify the characteristics used for establishing identity: something you are (e.g. male/female, DNA profile), have (e.g. SIM card), know/choose (e.g. password) or do/prefer (e.g. behaviour patterns). Forensic scientists should realize that the contribution of traces to infer identities is not limited to the provision of a suspect to court, but can serve other policing purposes and many criminological studies. For example, Bitzer et al. (2018, in this issue) evaluate the usefulness of forensic science not only as evidence provided for the court but also in an investigative perspective. They show and discuss the fact that forensic clues are useful for a multitude of purposes such as identification, reconstruction, case-linking, or even crime prevention.

Confronted with a huge amount of existing data, the question of how to handle big data arises in policing. It represents an opportunity as well as a challenge. On the one hand, we strive to collect or use as much data as possible to detect, identify, analyse, and solve crime problems. On the other hand, the relevant information is often hidden in the mass. Thus, the general idea should not be to collect more data but to find the reliable and relevant data to extract useful information. For instance, Chopin and Aebi (2018, in this issue) discuss the problem linked to the collection of too much information (as well as missing information). While analysing the
French ViCLAS database, they offered a strong empirical account of the misunderstandings surrounding the construction of a database to orient policing activities. Translating their results at an operational level, they demonstrate how focusing on situational variables would help crime analysts in their task of finding links between violent serial cases and supporting real-time investigations.

\section{Implications for management, education, and training}

What would be the use of a problem analysis, if it did not lead to a solution? Actions taken to handle and mitigate crimes can emerge from co-construction processes. For instance, forensic scientists, criminologists, and police officers may collaboratively work together during the investigation (Guéniat, 2018, in this volume). Moreover, Bitzer and colleagues (2018, in this volume) described key decisions in the management of an investigation: attend the crime scene, search and detect traces, collect relevant ones, analyse them, and finally use them for investigative, intelligence, and/or court purposes. The multiple knowledge dimensions used in decision-making processes (strategic considerations, criminal background, case-related situations, physical environment or utility) combine forensic and criminological theories and methods and might be used to define new management perspectives.

Finally, the need to educate professionals is also discussed from different perspectives. On the one hand, we need to educate criminologists and forensic scientists that will be able to handle cyberrelated crime data and to integrate themselves into quickly evolving crime professions. The idea is not to hire computer scientists or specialists that will address new technical issues, but 'crime' scientists that will be able to find the proper information science (IT) tools for the different problems the police practitioners are faced with (Ribaux 2018, in this issue). This might go from the extraction of numerical traces from a mobile phone to the 
monitoring of information transferred on the internet. The question was also raised about the need to perpetuate traditional expertise that is not routinely used (such as microtraces). A suggestion is made by Champod (2018, in this issue) to develop a clinical education model as used in medicine to increase, and generate knowledge of rarely used types of traces. Additional examples are also discussed by Baechler on how practice and research can feed academic and practical teaching (2018, in this issue). These contributions discuss the importance of cross-fertilization between research, education, and practice both from an academic and policing point of view. While routine responses of police services to problems have to be very quick, academic research can slow the pace to gain an overview of the situations and propose global solutions based on intelligence and crime analysis.

\section{Beyond the 'how to join' efforts and perspectives}

This special issue illustrates that it is impossible to address and solve real-life problems such as crime without collaboration. Crime-related problems are in fact interdisciplinary in nature. All kinds of knowledge, issued from many disciplines such as psychology, law, social science, computer science, chemistry, physics, biology, and so on, will be needed in interaction to study criminal activities. In this aspect, criminology and forensic science need to share their knowledge and methods to play a pivotal role. While computers and mobile phones have now replaced typewriting and to some extent, handwriting, we also need to transfer our competences to these new types of crime and traces. The current global digitalization transformation has profound impacts on crime, criminals and social reactions. The scale of change involves rethinking approaches to jointly manage mass data. New professions emerge and current practitioners should also be trained to adopt novel approaches to detect and interpret evolving forms of crime problems. This is a key venture to reframe and join disciplines within a critical-thinking approach. Current societal evolution undeniably requires to fasten policing, forensic science, and criminology for more than their own sake.

\section{References}

Baechler, S. (2018). 'Do We Need to Know Each Other? Bridging the Gap Between the University and the Professional Field.' Policing: A Journal of Policy and Practice, doi:10.1093/police/pax091.

Bitzer, S. Margot, P. and Delémont, O. (2018). 'Is Forensic Science Worth It?' Policing: A Journal of Policy and Practice, doi:10.1093/police/pax058.

Caneppele, S. and Aebi, M. F. (2018). 'Crime Drop or Police Recording Flop? On the Relationship between the Decrease of Offline Crime and the Increase of Online and Hybrid Crimes.' Policing: A Journal of Policy and Practice, doi:10.1093/police/pax055.

Casey, E. and Jaquet-Chiffelle, D. -O. (2018). 'Do Identities Matter?' Policing: A Journal of Policy and Practice, doi:10. 1093/police/pax034.

Champod, C. (2018). 'Forensic Laboratories: Is it All about Survival?' Policing: A Journal of Policy and Practice, doi:10. 1093/police/pax035.

Chopin, J. and Aebi, M. F. (2018). 'The Tree That Hides the Forest? Testing the Construct Validity of ViCLAS through an Empirical Study of Missing Data.' Policing: A Journal of Policy and Practice, doi:10.1093/police/pax062.

Esseiva, P. and Delémont, O. (2018). 'Into the Waste': How Forensic Science Recycle Them? Reflection on the Use of Waste to Understand Criminal Phenomenon .' Policing: A Journal of Policy and Practice, doi:10.1093/police/pax030.

Grossrieder, L. and Ribaux, O. (2018). 'Towards Forensic Whistleblowing? From Traces to Intelligence.' Policing: A Journal of Policy and Practice, doi:10.1093/police/pax039.

Guéniat, O. (2018). 'In Vestige @ and Police Management?' Policing: A Journal of Policy and Practice, doi:10. 1093/police/pax044.

Ribaux, O. (2018). 'Reframing Forensic Science and Criminology for Catalyzing Innovation in Policing Practices.' Policing: A Journal of Policy and Practice, doi:10.1093/police/pax057. 